\title{
Late administration of a specific COX-2 inhibitor does not treat and/or prevent progression of gastric tumors in rats submitted to duodenogastric reflux procedure ${ }^{1}$
}

\author{
Paulo Antônio Rodrigues', Luiz Eduardo Naresse ${ }^{\mathrm{II}}$, Maria Aparecida Marchesan Rodrigues ${ }^{\mathrm{III}}$, Shoiti Kobayasi ${ }^{\mathrm{IV}}$
}

${ }^{\mathrm{I}} \mathrm{PhD}$, Assistant Professor, Departament of Surgery and Orthopedics, Faculty of Medicine, UNESP, Botucatu-SP, Brazil. Conception, design, intellectual and scientific content of the study; interpretation of data; technical procedures; acquisition of data; manuscript writing.

${ }^{I I} \mathrm{PhD}$, Associate Professor, Departament of Surgery and Orthopedics, Faculty of Medicine, UNESP, Botucatu-SP, Brazil. Technical procedures.

IIIPhD, Full Professor, Departament of Pathology, Faculty of Medicine, UNESP, Botucatu-SP, Brazil. Histophatological analysis.

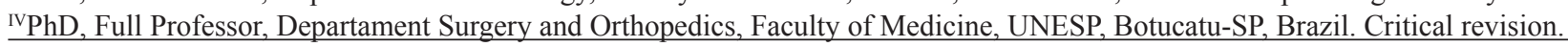

\section{ABSTRACT}

PURPOSE: To assess whether late introduction of a specific COX-2 inhibitor (Meloxicam) can treat and/or prevent the progression of tumors in the stomach of rats submitted to duodenogastric reflux.

METHODS: Seventy five male Wistar rats, weighing 150 grams, were submitted to the induction of duodenogastric reflux through the pylorus. At 36 weeks of follow-up were established three experimental groups: DGR36 sacrificed immediately, DGR54 and DGR54MLX both sacrificed at $54^{\text {th }}$ week of follow-up . The animals of the latter group were fed with a rat chow premixed with Meloxicam (2.0 mg/ $\mathrm{kg}$ feed; $0.3 \mathrm{mg} / \mathrm{kg}$ bw / day) and the other two with standard rat chow. The lesions found in the pyloric mucosa and gastrojejunal anastomosis were analyzed macroscopically and histologically. For statistical analysis was adjusted a generalized linear model assuming a binomial distribution with LOGIT link function.

RESULTS: No significant differences were found when comparing the incidences of benign tumor lesions (Adenomatous Hyperplasia), $\mathrm{p}=0.4915$, or malignant (Mucinous Adenocarcinoma), $\mathrm{p}=0.2731$, among groups.

CONCLUSION: Late introduction of specific COX-2 inhibitor (Meloxicam) did not treat and was not able to prevent the progression of tumoral lesions induced by duodenogastric reflux in the rat stomachs.

Key words: Adenocarcinoma. Stomach. Chemoprevention. Cyclooxygenase Inhibitors. Rats. 


\section{Introduction}

Several studies indicate that COX-2 expression is a relatively early event during stomach carcinogenesis process ${ }^{1}$. The results of COX expression analysis have shown that COX2 is increased in gastric cancer, but not in normal mucosa suggesting that this enzyme plays an important role in the gastric carcinogenesis ${ }^{2}$. Some studies have suggested that non-steroidal anti-inflammatory drugs (NSAIDs) are associated with reduced incidence of gastric cancer ${ }^{3,4}$. The inhibitory effect of NSAIDs on the Cox action, and consequently the decrease in the production of prostaglandins is identified as the main chemopreventive effect of these drugs. Prostaglandins act as promoter of carcinogenesis because the reduction of their levels is associated to a decrease in the carcinogenesis and instead sustained increase is associated with a facilitating effect for the development of tumors ${ }^{5}$.

Recently two studies performed in rats submitted to a surgical procedure of duodenogastric reflux (DGR) have shown that oral administration of specific COX-2 inhibitors, Meloxicam in the first ${ }^{6}$ and Celecoxib in the latter ${ }^{7}$ can prevent the development of gastric proliferative lesions in gastric mucosa. In these studies, the oral intake of specifics COX-2 inhibitors started as soon as DGR was induced and; therefore, still without established proliferative lesions at the gastric mucosa. However, it is poorly investigated if oral intake of Meloxicam could be a preventive drug when gastric proliferative lesions were already present. Such study would have clinical relevance since thousands of patients underwent to a surgical treatment for peptic ulcers can potentially have a greater or lesser degree of DGR. It has also been shown that some patients underwent to partial gastrectomies for treatment of peptic ulcer disease show a higher risk for of development of gastric stump cancer than those non-gastrectomized. This risk is correlated with the intensity of DGR, since cancer incidence is higher in patients underwent to a Billroth II type gastrectomies where DGR would be more intense. Also is known through experimental studies that induction of DGR alone is enough for the development of gastric cancer in the rat stomach. Therefore, to test if late administration of a specific COX-2 inhibitor (Meloxicam) can treat and/or prevent the progression of gastric tumors in rats submitted to duodenogastric reflux procedure we designed the present study.

\section{Methods}

The study follows the Council for International Organization of Medical Sciences (CIOMS) ethical code for animal experimentation. A series of 75 male Wistar rats weighing
$150 \mathrm{~g}$ were fed a standard rat chow and tap water ad libitum. The animals were kept under standard conditions in a controlled room kept at a $22 \pm 2{ }^{\circ} \mathrm{C}$ and a $12 / 12 \mathrm{~h} \mathrm{light/dark} \mathrm{cycle.} \mathrm{After}$ initial acclimation, they were submitted to the surgical procedure to obtain the duodenogastric reflux through the pylorus (DGR). After intra-peritoneal anesthesia with sodium pentobarbital (30 $\mathrm{mg} / \mathrm{kg}$ body wt) a midline laparotomy was performed. Then, 1 $\mathrm{cm}$ anastomosis was constructed between a jejunal segment (4 $\mathrm{cm}$ ahead to the Treitz's ligament) and stomach anterior wall. At sequence, the jejunum was divided and both cut ends had been closed $1 \mathrm{~cm}$ before the gastrojejunal anastomosis, in order to allow the flow of the duodenal content to the stomach (Figure 1).

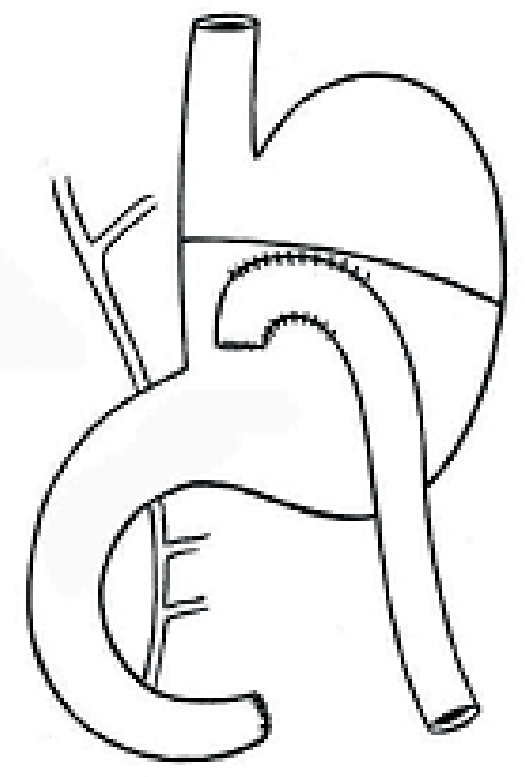

FIGURE 1 - Schematic representation of DGR procedure.

At the $36^{\text {th }}$ week after DGR procedure, all 36 survival animals were randomly divided into three experimental groups and were killed under sodium pentobarbital ( $30 \mathrm{mg} / \mathrm{kg}$ body $\mathrm{wt})$ anesthesia in following periods:

1- DGR36: 12 animals sacrificed at the $36^{\text {th }}$ week.

2- DGR54: 10 out of 12 animals sacrificed at the $54^{\text {th }}$ week. Two deaths belatedly occurred during follow-up.

3-DGR54MLX: from 36 weeks of follow-up 12 animals started to receive a rat chow premixed with Meloxicam $(2.0 \mathrm{mg} / \mathrm{kg}$ chow; $0.3 \mathrm{mg} / \mathrm{kg}$ bw/day) and sacrificed at the $54^{\text {th }}$ week.

After DGR surgery, the animals had access only to tap water; solid food was allowed after $24 \mathrm{~h}$. Body weight was measured weekly.

At the necropsy, abdominal cavity was examined for the presence of ascites, fistulae, prominent lymphatic nodules and carcinomatosis. The stomach was removed, opened along the great 
curvature, rinsed in saline solution and examined. The lesions found in the glandular stomach and at the gastrojejunal stoma were photographed and their macroscopic characteristics registered. The specims were spread on a cork plate on the serosal surface and fixed by immersion in $10 \%$ buffered formalin. Each stomach was sectioned into successive longitudinal cuts including the oxyntic and the pyloric mucosa. The gastrojejunal portion was submitted to successive transverse cuts including the oxyntic mucosa and the jejunal loop. The specimens were embedded in paraffin and stained with hematoxylin/eosin. All histopathological analyses were performed by the same investigator who was unaware of the experimental group to which the specimen belonged.

For statistical analysis was adjusted a generalized linear model assuming a binomial distribution with LOGIT link function. Differences were considered significant when the $p$ value was $<$ 0.05 .

\section{Results}

\section{Macroscopy}

All three experimental groups presented huge polypoid lesions (Figure 2) in the pyloric mucosa and, more frequently, at the gastrojejunal stoma $(p<0.0001)$. In the DGR36, 1 out of 12 rats $(8.3 \%)$ developed polypoid lesions in the pyloric mucosa and 5 out of 12 rats $(41.6 \%)$ at the gastrojejunal stoma. Similar polypoid lesions are found in DGR54, 5 out of 10 rats $(50 \%)$ at the gastrojejunal stoma and none at the pyloric mucosa. In DGR54MLX we found polypoid lesions at the gastrojejunal stoma in five out of 12 rats $(41.6 \%)$ and at the pyloric mucosa 1 out of 12 $(8.3 \%)$. No remarkable macroscopic alterations were found at the squamous portion of gastric mucosa or into the abdominal cavity (Table 1)

TABLE 1 - Frequency (\%) and distribution of macroscopic lesions diagnosed in the experimental groups.

\begin{tabular}{ccc}
\hline Groups & Local & Polypoid lesion \\
\hline $\begin{array}{c}\text { DGR36 } \\
\mathbf{n}=\mathbf{1 2}\end{array}$ & $\begin{array}{c}\text { Stoma } \\
\text { Pyloric Mucosa }\end{array}$ & $5(41.6 \%)^{1}$ \\
$1(8.3 \%)$ \\
\hline $\begin{array}{c}\text { DGR54 } \\
\mathbf{n}=\mathbf{1 0}\end{array}$ & $\begin{array}{c}\text { Stoma } \\
\text { Pyloric Mucosa }\end{array}$ & $5(50 \%)^{1}$ \\
\hline $\mathbf{n = 1 2}$ & Stoma & $5(0 \%)$ \\
\hline Total & Pyloric Mucosa & $1(8.3 \%)$ \\
\hline
\end{tabular}

${ }^{1} \mathrm{p}<0.0001$ for Stoma vs. Pyloric Mucosa in all groups.

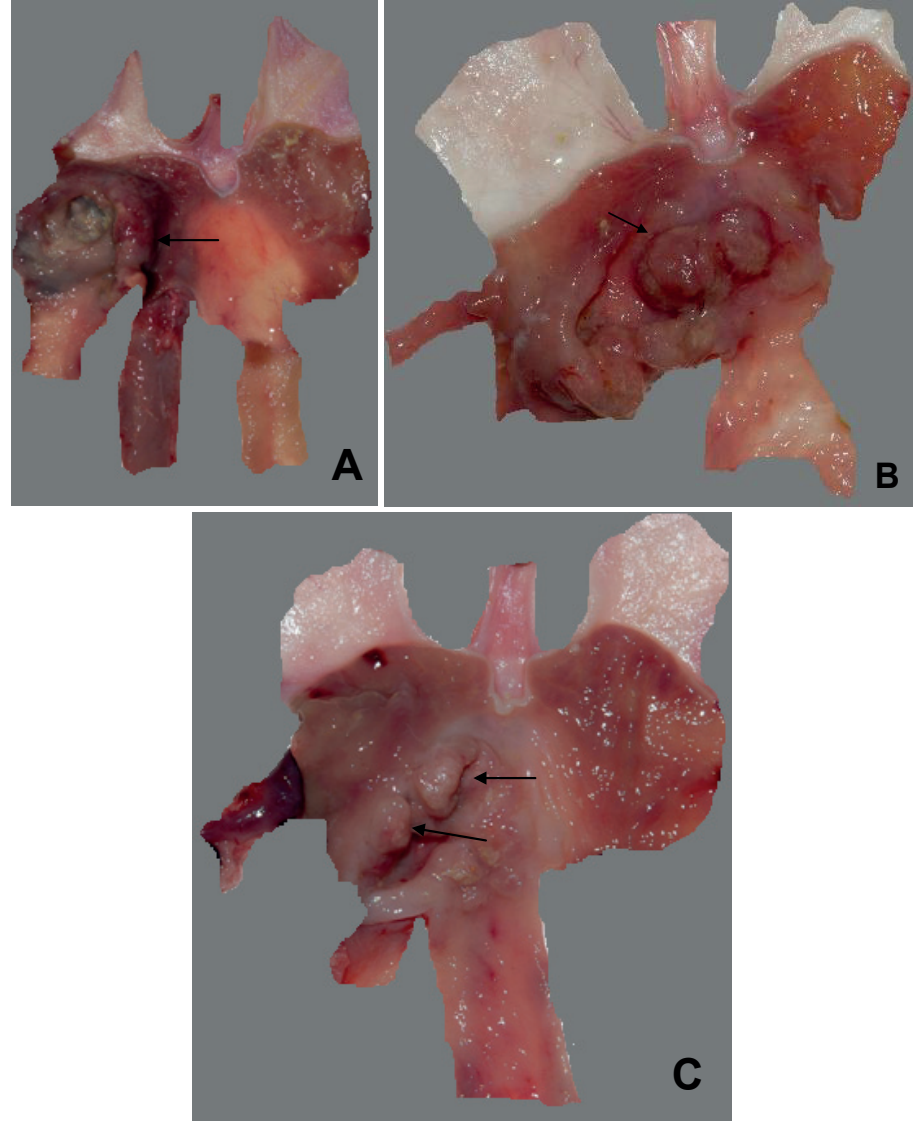

FIGURE 2 - Macroscopic appearance of the entire stomach showing polypoid lesions at the gastrojejunal stoma (arrows) in DGR36 (A), DGR54 (B) and DGR54MLX (C).

\section{Histology}

Data for the distribution of the histological lesions at the pyloric mucosa and at the gastrojejunal anastomosis are shown in Table 2. We found two types of proliferative lesions: Adenomatous Hyperplasia (AH) characterized by proliferating glandular structures and foveolar epithelium, with cystic dilatations, without cellular atypia and without invasion of the muscular layer and may show endophytic or exophytic growth; Mucinous Adenocarcinomas (MA) diagnosed when proliferating glandular structures with cystic dilatation, cellular atypia and invasion of muscular layer were observed (Figure 3). Our study showed that late administration of Meloxicam was no effective to prevent gastric proliferative lesions in rats from the DGRMLX group since $\mathrm{AH}$ was observed in $50 \%$ of treated rats compromising the gastrojejunal stoma, and in $41.6 \%$ the pyloric mucosa. Moreover, MA was also observed in $16.6 \%$ of treated rats of this group at the gastric stoma. 
TABLE 2 - Frequency (\%) and distribution of histological lesions diagnosed in the experimental groups.

\begin{tabular}{cccc}
\hline Groups & Local & $\begin{array}{c}\text { Adenomatous } \\
\text { Hyperplasia }\end{array}$ & $\begin{array}{c}\text { Mucinous } \\
\text { Adenocarcinoma }\end{array}$ \\
\hline $\begin{array}{c}\text { DGR36 } \\
\mathrm{n}=12\end{array}$ & $\begin{array}{c}\text { Stoma } \\
\text { Pyloric }\end{array}$ & $\begin{array}{c}4(33.3 \%)^{1} \\
4(33.3 \%)\end{array}$ & $\begin{array}{c}1(8.3 \%)^{2} \\
0(0 \%)\end{array}$ \\
\hline Mucosa & & \\
DGR54 & Stoma & $6(60 \%)^{1}$ & $0(0 \%)^{2}$ \\
$\mathrm{n}=10$ & Pyloric & $4(40 \%)$ & $0(0 \%)$ \\
& Mucosa & & \\
DGR54MLX & Stoma & $6(50 \%)^{1}$ & $2(16.6 \%)^{2}$ \\
$\mathrm{n}=12$ & Pyloric & $5(41.6 \%)$ & $0(0 \%)$ \\
\hline Total & Mucosa & & 3
\end{tabular}

${ }^{\mathrm{P}} \mathrm{p}=0.4915$ for comparison of incidences of $\mathrm{AH}$ between the groups.

${ }^{2} \mathrm{p}=0.2731$ for comparison of incidences of MA between the groups.
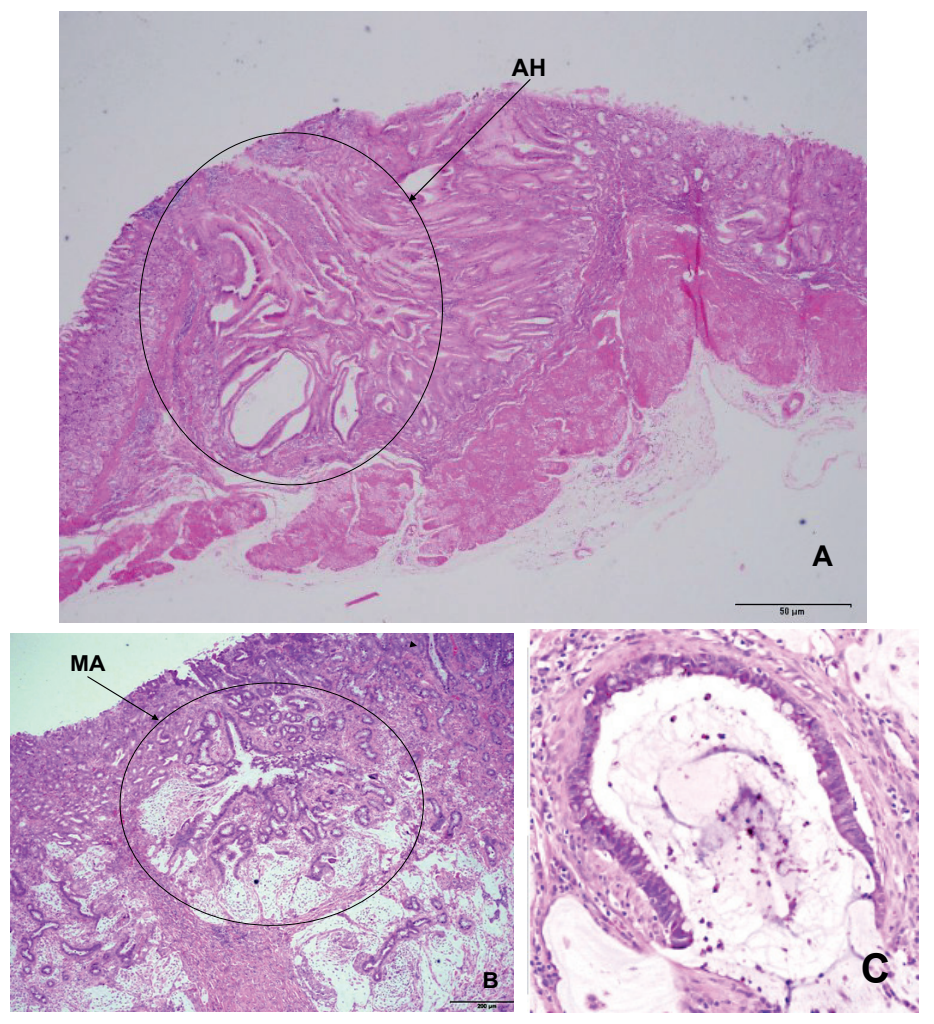

FIGURE 3 - (A) Endophytic form of Adenomatous Hyperplasia, (H\&E, $\mathrm{x} 40$ ); (B) Mucinous Adenocarcinoma locate at the gastrojejunal stoma, (H\&E, x40); (C) Detail of Mucinous adenocarcinoma showing atypical glandular cells, (H\&E, x100).

\section{Discussion}

Aspirin and other non-steroidal anti-inflammatory drugs (NSAIDs) inhibit prostaglandins synthesis via the cyclooxygenase (COX) enzyme. The capacity for the NSAIDs in inhibiting $\mathrm{COX}$ action and consequently decrease the prostaglandins production is pointed as the main factor for the chemo-preventive effect of these drugs ${ }^{8}$. Prostaglandins exert stimulatory effects on cell proliferation, attenuate apoptosis, modulate the expression of surface molecules that increase the ability to invasion and metastasis, stimulate angiogenesis, attract and activate macrophages and produce immunosuppression through their effects on distinct lymphocyte subpopulations ${ }^{9}$. Although there is substantial evidence that the surrounding stroma plays an important role in cancer development, the macrophages may play a key role in gastric carcinogenesis through inflammation associated with enhanced COX-2 expression ${ }^{10}$. There are two isoforms of cyclo-oxygenase, COX-1 and COX-2. The former is constitutively expressed in most tissues and plays an important role in maintaining homeostasis and the latter is induced by cytokines, tumor promoters, and hormones. Investigators have demonstrated that NSAIDs reduce epithelial proliferation, and inhibit tumor growth and tumor-induced angiogenesis ${ }^{11}$. Aspirin and NSAIDs have demonstrated the ability to suppress growth of gastric cancer, and inducing apoptosis, in gastric cancer cell lines ${ }^{12}$. This is achieved via an up-regulation of pro-apoptotic proteins, including bax and bak, leading to activation of caspase-3, a central component regulating mammalian cell death ${ }^{13}$. It is probably that overexpression of COX-2 in gastric cancer tissue specimens could facilitate lymphatic invasion and metastasis ${ }^{14}$. Several studies indicate that COX-2 expression is a relatively early event during carcinogenesis into the stomach ${ }^{1}$. COX-2 expression increases in the early stage of carcinogenesis when inflammation with cell infiltration is strong, thereby being involved in the proliferation and survival of immature epithelial cells. Thus, COX-2 expression is maximal in the early stage of inflammation, then decreases, but remains high 6 .

When we induced the reflux of duodenal contents through the pylorus, the compounds of duodenal contents cause a great injury to the gastric mucosa and therefore may promote a huge oxidative stress (OS), which is considered a potent inducer of the transcription growth factor epithelium (VEGF), which interacts closely with the COX-2 in the neoangiogenesis which supporting the carcinogenesis. OS is a mutagen capable of damaging cellular DNA, while proteins responsible for its repair, and therefore, the proper inflammatory process may potentially act as initiator cancer through oxygen free radicals and nitric oxide generation ${ }^{15,16}$.

Our results have demonstrated that late introduction of specific COX-2 inhibitor (Meloxicam) did not treat and was not able to prevent the progression of proliferative lesions at the gastric mucosa submitted to reflux of duodenal contents. 
We found no statistical difference among the groups DGR54 and DGR54MLX in regarding to Adenomatous Hyperplasia or Adenocarcinoma. As COX-2 expression is a relatively early event during carcinogenesis into the stomach, is possible to suggest that when Meloxicam was administered the inhibition of COX2 probably was no longer an important step to interrupt the carcinogenesis process. The fact that one adenocarcinoma was diagnosed in one animal of DGR36 shows that carcinogenesis process was in an advanced stage when the drug administration was started. Possibly the lesions already had reached a point of no return of the carcinogenesis process, characterized by autonomy, maintenance or even stimulation of this process mediated by the effect of unrelated promoters of carcinogenesis not linked with the primary cause of injuries. Another possibility to explain the negative result could be that Meloxicam dosage was insufficient to block COX-2 in these experimental conditions. More studies need to be done for clarify the potential use of COX-2 specific inhibitors against carcinogenesis process.

\section{Conclusion}

Late introduction of specific COX-2 inhibitor (Meloxicam) did not treat and was not able to prevent the progression of tumoral lesions induced by duodenogastric reflux in the rat stomachs.

\section{References}

1- Day Y, Wang WH. Non-steroidal anti-inflammatory drugs in prevention of gastric cancer. World $\mathrm{J}$ Gastroenterol. 2006;12(18):2884-8.

2- Ristimaki A, Honkanen N, Jankala H, Sipponen P, Harkonem M. Expression of cyclo-oxygenase-2 in human gastric carcinoma. Cancer Res. 1997;57:1276-80.

3- Thun MJ, Namboodiri MM, Calle EE, Flanders WD, Heath CW Jr. Aspirin use and risk of fatal cancer. Cancer Res. 1993;53:1322-7.

4- $\quad$ Akre K, Ekstrom AM, Signorello LB, Hanson LE, Nyren O. Aspirin and risk for gastric cancer: a population-based case-control study in Sweden. Br J Cancer. 2001;84:965-8.

5- Grau CJJ. Inibidores de la ciclooxigenase-2. Rev Clin Esp. 2005;205(9):446-56.

6- Oba M, Miwa K, Fujimura T, Harada S, Sasaki S, Hattori T. Chemoprevention of glandular stomach carcinogenesis through duodenogastric reflux in rats by a COX-2 inhibitor. Int J Cancer. 2008;123:1491-8.

7- Ramos TRR, Lourenço LG, Jucá MJ, Costa V, Leal AT. Chemoprevention by celecoxib in reflux-induced gastric adenocarcinoma in Wistar rats that underwent gastrojejunostomy. Acta Cir Bras. 2009;24(3):189-94.

8- Chen CN, Sung CT, Lin MT, Lee PH, Chang KJ. Clinicopathologic association of cyclooxygenase 1 and cyclooxygenase 2 expression in gastric adenocarcinoma. Ann Surg. 2001;233:183-8.
9- Cao Y, Prescott SM. Many actions of cyclo-oxygenase-2 in cellular dynamics and in cancer. J Cell Physiol. 2002;190:279-86.

10- Tlsty TD, Coussens LM. Tumor stroma and regulation of cancer development. Ann Rev Pathol. 2006;1:119-50.

11- Smith ML, Hawcroft G, Hull MA. The effect of non-steroidal antiinflammatory drugs on human colorectal cancer cells: evidence of different mechanisms of action. Eur J Cancer. 2000;36:664-74.

12- Sawaoka H, Kawano S, Tsuji S. Effects of NSAIDs on proliferation of gastric cancer cells in vitro: possible implication of cyclooxygenase-2 in cancer development. J Clin Gastroenterol. 1998;27:S47-52.

13- Zhou XM, Wong BCY, Fan XM. Non-steroidal anti-inflammatory drugs induce apoptosis in gastric cancer cells through up-regulation of bax and bak. Carcinogenesis. 2001;22:1393-7.

14- Murata H, Kawano S, Tsuji S. Cyclooxygenase-2 overexpression enhances lymphatic invasion and metastasis in human gastric carcinoma. Am J Gastroenterol. 1999;94:451-5.

15- Hussain SP, Hofseth LJ, Harris CC. Radical causes of cancer. Nature Rev Cancer. 2003;3:276-85.

16- Coussens LM, Werb Z. Inflammation and cancer. Nature. 2002;420:860-7.

\section{Acknowledgments}

We are grateful to Professor César Tadeu Spadella for critical review of the study, formatting and proofreading the manuscript in English and to Maria Cecilia Salgado Mercadante by the invaluable help in performing the surgical procedures.

\section{Correspondence:}

Paulo Antônio Rodrigues

Alameda das Grevílias, 300

18607-360 Botucatu - SP Brasil

Tel.: (55 14)3880 1435

paulor@,fmb.unesp.br

Received: February 20, 2013

Review: April 18, 2013

Accepted: May 17, 2013

Conflict of interest: none

Financial source: none

${ }^{1}$ Research performed at Laboratory of Surgical Technique and Experimental Surgery, Faculty of Medicine, Sao Paulo State University (UNESP), Botucatu-SP, Brazil. 